\title{
A competitividade da carne bovina brasileira à luz das cinco forças de Porter: estudo de caso em um frigorífico na região noroeste do Rio Grande do Sul
}

The competitiveness of brazilian beef in the light of Porter's five forces: a case study in a slaughterhouse in the northwest region of Rio Grande do Sul

La competitividad de la carne de vacuno brasileña a la luz de las cinco fuerzas de Porter: un estudio de caso en un matadero en la región noroeste de Rio Grande do Sul

Recebido: 09/08/2021 | Revisado: 13/08/2021 | Aceito: 14/08/2021 | Publicado: 16/08/2021

Darlan Ariel Prochnow

ORCID: https://orcid.org/0000-0003-3699-074X Universidade Regional do Noroeste do Estado do Rio Grande do Sul, Brasil E-mail: darlan.prochnow@sou.unijui.edu.br

Raissa Castro Schorn

ORCID: https://orcid.org/0000-0001-6454-2720 Universidade Regional do Noroeste do Estado do Rio Grande do Sul, Brasil E-mail: raissa.schorn@ sou.unijui.edu.br

Argemiro Luís Brum

ORCID: https://orcid.org/0000-0002-8763-9514 Universidade Regional do Noroeste do Estado do Rio Grande do Sul, Brasil E-mail: argelbrum@unijui.edu.br

Nelson José Thesing

ORCID: https://orcid.org/0000-0001-7123-0717 Universidade Regional do Noroeste do Estado do Rio Grande do Sul, Brasil E-mail: nelson.thesing@unijui.edu.br

Sérgio Luís Allebrandt

ORCID: https://orcid.org/0000-0002-2590-6226 Universidade Regional do Noroeste do Estado do Rio Grande do Sul, Brasil E-mail: allebr@unijui.edu.br

Cleiton Jardel Carneiro

ORCID: https://orcid.org/0000-0001-5606-0932 Universidade Regional do Noroeste do Estado do Rio Grande do Sul, Brasil E-mail: cleiton.carneiro@sou.unijui.edu.br

Airton Adelar Mueller

ORCID: https://orcid.org/0000-0001-6270-5856 Universidade Regional do Noroeste do Estado do Rio Grande do Sul, Brasil E-mail: airton.mueller@unijui.edu.br

Alexandra Alf Gallon

ORCID: https://orcid.org/0000-0002-2462-5246 Universidade Regional do Noroeste do Estado do Rio Grande do Sul, Brasil E-mail: alexandra.alf@sou.unijui.edu.br

\begin{abstract}
Resumo
O mercado da carne bovina apresenta dados que colocam o Brasil em posição de destaque no cenário global, tanto como produtor quanto como consumidor. Deste modo, o presente estudo tem, como objetivo geral, investigar a competitividade da carne bovina brasileira, à luz do modelo das cinco forças de Porter, através do estudo em uma indústria frigorífica da região Noroeste do rio Grande do Sul. A metodologia da pesquisa conta com o estudo de caso único. Com abordagem qualitativa, a pesquisa foi operacionalizada através de entrevista semiestruturada com gestor e a respectiva análise de conteúdo, para trabalhar os elos da cadeia produtiva da carne bovina, às variações de demanda dos consumidores e as possíveis mudanças culturais e econômicas. Os achados da pesquisa apontam oscilação positiva na demanda pela carne bovina, o que retrata a força deste mercado, tanto no cenário nacional como internacional. Ainda, algumas ameaças à essa demanda são presentes, como o crescimento da cultura vegetariana.
\end{abstract}

Palavras-chave: Carne bovina; Indústria frigorífica; Estratégia; Competitividade.

\section{Abstract}

The beef market presents data that place Brazil in a prominent position in the global scenario, both as a producer and as a consumer. Thus, the present study has, as a central objective, to investigate the competitiveness of Brazilian beef, in the light of the Porter's five forces model. The research methodology relies on a single case study, carried out in a slaughterhouse located in the Northwest Region of the state of Rio Grande do Sul. With a qualitative approach, the 
research was operationalized through a semi-structured interview with a manager and the respective content analysis, to work the links in the beef production chain, to variations in consumer demand and possible cultural and economic changes. The research findings point to a positive fluctuation in the demand for beef, which shows the strength of this market, both in the national and international scenario. Still, some threats to this demand are present, such as the growth of vegetarian culture.

Keywords: Beef; Slaughterhouse; Strategy; Competitiveness.

\section{Resumen}

El mercado de la carne vacuna presenta datos que colocan a Brasil en una posición destacada en el escenario global, tanto como productor como como consumidor. Así, el presente estudio tiene como objetivo general investigar la competitividad de la carne vacuna brasileña, a la luz del modelo de cinco fuerzas de Porter, a través de un estudio en una industria frigorífica en la región noroeste de Rio Grande do Sul. La metodología de investigación cuenta en el estudio de caso único. Con un enfoque cualitativo, la investigación se llevó a cabo a través de una entrevista semiestructurada con un gerente y el respectivo análisis de contenido, para trabajar los eslabones en la cadena productiva de la carne, las variaciones en la demanda de los consumidores y los posibles cambios culturales y económicos. Los hallazgos de la investigación apuntan a una oscilación positiva en la demanda de carne vacuna, lo que refleja la fortaleza de este mercado, tanto a nivel nacional como internacional. Aún así, existen algunas amenazas a esta demanda, como el crecimiento de la cultura vegetariana.

Palabras clave: Carne de res; Industria de la refrigeración; Estrategia; Competitividad.

\section{Introdução}

O Brasil se destaca como um dos mais importantes produtores de carne bovina no mundo. Essa posição é confirmada pelos números, que envolvem tanto o setor produtivo como o mercado. Em 2015 o país alcançou a marca de maior rebanho (209 milhões de cabeças), como o segundo maior consumidor (38,6 kg/habitante/ano) e o segundo maior exportador (1,9 milhões toneladas) de carne bovina no mundo, com abate de mais de 39 milhões de cabeças. Ainda, os números apontam que $80 \%$ da carne bovina consumida no Brasil é produzida no próprio país, e a indústria frigorífica possui capacidade de abate de quase 200 mil bovinos por dia (Embrapa, 2020).

Os agentes ou elos da cadeia da carne bovina, movidos pela necessidade de aumentar a sua competitividade, buscam abandonar a forma predominante de relacionamento atual, que é de conflito permanente, entre os participantes da cadeia. Deste modo, novas formas de organização estão sendo buscadas, utilizando como referência as experiências das cadeias de aves e suínos, as quais têm obtido ganhos de competitividade a partir de maior formalização das transações dos produtores com a indústria (Ferreira \& Padula, 2002).

Portanto, segundo Braga (2010), a competitividade empresarial, ligada às necessidades de adaptação ao mercado, aponta grandes exigências para as organizações do agronegócio, cultiva elevado grau risco e com pouca previsibilidade, típico das atividades agropecuárias. Assim, a competitividade da carne bovina brasileira está atrelada a um conjunto de fatores vinculados à sua cadeia produtiva, sendo a indústria frigorífica o importante elo da cadeia responsável pelo beneficiamento da produção.

Em se tratando de competitividade na indústria frigorífica, o modelo teórico recomendado para a análise, indica as cinco forças competitivas de Porter (1990, p. 3) "as regras da concorrência estão englobadas em cinco forças competitivas: a entrada de novos entrantes, a ameaça de substitutos, o poder de negociação dos compradores, o poder de negociação dos fornecedores e a rivalidade entre os concorrentes existentes”. Essas forças são as lentes que vão auxiliar na pesquisa, que possui como objetivo analisar a competitividade da carne bovina brasileira, através de estudo de caso em uma indústria frigorífica, localizada na região Noroeste do estado do Rio Grande do Sul, que possuí uma sólida presença no mercado da carne bovina, atuando há mais de duas décadas no comércio de cortes tradicionais e especiais. A pesquisa segue os apontamentos de Vieira et al. (2020), uma vez que estes autores concluem que é preciso estudar o funcionamento dos sistemas agroindustriais da carne bovina, para que se possa encontrar explicações acerca do comportamento dos preços na comercialização deste produto. 
Por fim, a estrutura do artigo contempla a Introdução, o Referencial Teórico, que apresenta a cadeia produtiva da carne bovina e mercado consumidor, bem como as cinco forças competitivas de Porter. A seguir, a Metodologia do trabalho indica como foi realizada a pesquisa, dando condições para a descrição e análise dos Resultados e por consequência, as Considerações Finais.

\section{Referencial Teórico}

Este tópico contém os conceitos e informações empregados para o desenvolvimento da pesquisa. Inicialmente é destacada a cadeia produtiva da carne bovina, a qual contém, em seus elos, a indústria frigorífica. Após é apresentado o mercado da carne bovina, especialmente no cenário brasileiro.

\subsection{Cadeia produtiva da carne bovina}

A análise das alianças estratégicas entre empresas, especialmente no agronegócio, vem crescendo na literatura (Ferreira \& Barcellos, 2006). De acordo com Batalha (1997), as cadeias produtivas são a soma de todas as operações de produção e comercialização, que foram necessárias, para passar de uma ou várias matérias-primas de base, a um produto final, isto é, até que o produto chegue às mãos de seu usuário, seja ele, um particular ou uma organização. Nesta pesquisa, a contribuição teórica se concentra na cadeia produtiva da carne bovina.

A cadeia produtiva da carne bovina faz parte de um complexo agroindustrial, que inclui atividades relacionadas aos suprimentos de insumos, destinados às fazendas/granjas (vacinas, base genética, pastagem, etc.), aos frigoríficos-abatedouros (abate e processamento) e à distribuição (açougues e supermercados) visando, por fim, o atendimento do consumidor final (nacional e internacional), sendo que a temática transporte perpassa todos os elos da cadeia (Zucchi \& Caixeta-filho, 2010). A Figura 1 representa o conjunto de elos que compõem a cadeia produtiva da carne bovina.

Figura 1: Cadeia produtiva da carne bovina.
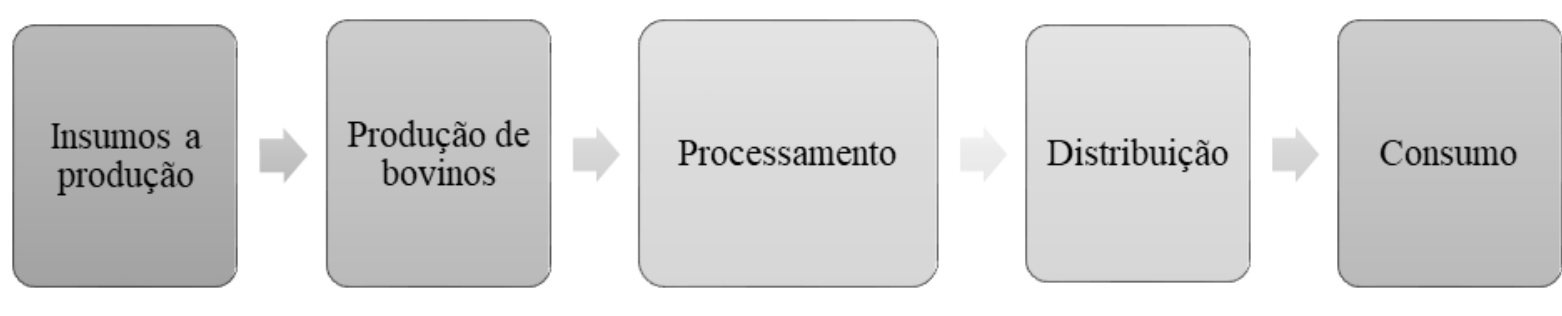

Fonte: Autores, com base em Buainain e Batalha (2007).

Portanto, o primeiro elo da cadeia da carne bovina, são os insumos compostos por todo e qualquer elemento diretamente necessário para o processo de produção, representado pela movimentação de várias indústrias: veterinária, máquinas e equipamentos, adubos, sementes e agroquímicos, alimentos e suplementos (Buainain \& Batalha, 2007).

Ao concluir o processo da engorda, os bovinos são abatidos, e a carne é processada pela indústria frigorífica. Em relação ao processo de preparação das carcaças, distribuição dos quartos (novo processamento) e desossa, podem ser realizados no próprio frigorífico, que faz o abate dos animais, em entrepostos especializados em desossa ou nos açougues. Quando realizados em frigoríficos, a desossa é associada ao processo de embalagem da carne. Essa operação avançou nos últimos anos, porque os cortes desossados passaram a ser embalados a vácuo, e assim podem ir do frigorífico direto para o consumidor final, sendo assim, reduz o custo operacional e cresce a aplicação em relação aos cortes sem osso que acabam sendo oferecidos em larga escala no processo de distribuição (Embrapa, 2020). A Figura 2 apresenta o processamento da carne bovina pela indústria frigorífica. 
Figura 2: Processamento da carne bovina pela indústria frigorífica.
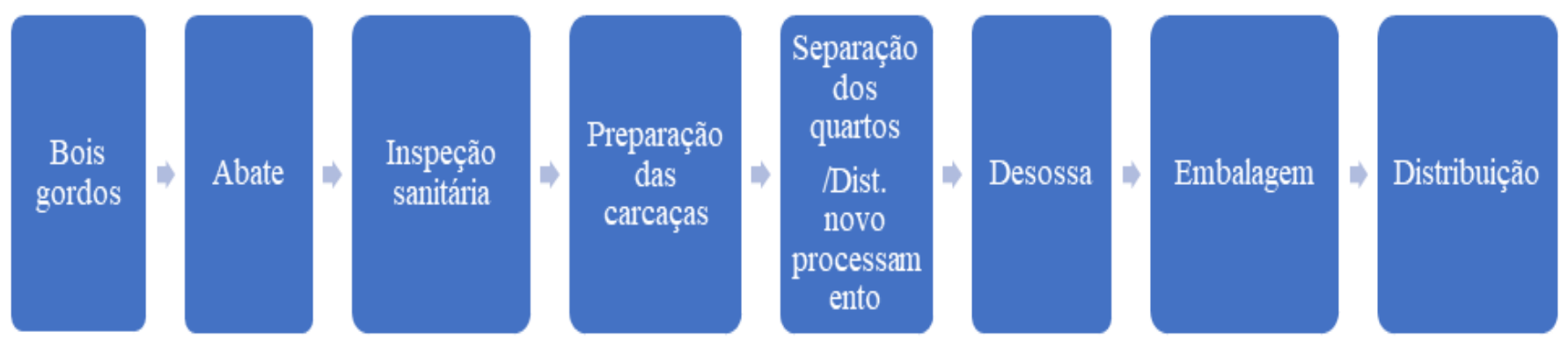

Fonte: Autores, a partir de dados da Embrapa (2020).

No que diz respeito a distribuição e consumo, estima-se que a distribuição da carne para o consumidor final, segundo locais de comercialização, sejam: supermercado, hipermercados, restaurantes, hotéis, açougues, boutiques de carne e refeições industriais. Em relação aos supermercados, eles constituíam até o ano de 2000 aproximadamente 35 mil estabelecimentos em território brasileiro e açougues (dentro de supermercados) respondem 18\% das vendas dos supermercados (IEL, CNA E SEBRAE, 2000). No Brasil, o transporte de carne bovina é realizado, de forma predominante, por rodovias e, em seguida, exportado, principalmente por via marítima, aos compradores (Embrapa, 2020).

\subsection{Mercado da carne bovina}

O maior produtor de carne bovina do mundo são os Estados Unidos, com o fornecimento de 17,2\% na cadeia de carne mundial, isso equivale a 11,0 milhões de toneladas de equivalente por carcaça (TEC). Embora possua um rebanho inferior ao do Brasil, os Estados Unidos estão posicionados como o segundo país que mais contribui com o abastecimento global de carne, e sua contribuição alcança níveis de 15,3\%, o que corresponde a 12,3 TEC. Em terceiro lugar encontra-se a união europeia, participando com 10,6\% da demanda mundial de carne (ABIEC, 2019).

A pecuária de corte brasileira se consolidou nos últimos anos como importante produtora de alimentos e se inseriu no mercado internacional como ator competitivo, ocupando ora a primeira ora a segunda colocação entre os maiores exportadores. Atualmente, o Brasil possui o maior rebanho comercial do mundo (Reis, 2018), isso contribui para o PIB brasileiro, com aproximadamente R \$ 597,22 bilhões ao ano, totalizando uma contribuição de 8,7\% em 2018 no PIB. Em dez anos, essa foi a maior cooperação da pecuária e essa elevação deve-se, em parte, aos faturamentos obtidos pelos frigoríficos, que girou em torno de $\mathrm{R} \$ 144,9$ bilhões, configurando um crescimento de 16,2\% comparado ao ano de 2017 (Reis, 2018; ABIEC, 2019).

A maior parte da carne bovina comercializada no Brasil é vendida in natura, que é o produto com menor valor agregado, tendo em vista possuir uma maior escala de produção. No ano de 2015 o Brasil se posicionou como o segundo maior consumidor (38,6 kg/habitante/ano) e o segundo maior exportador (1,9 milhões toneladas) de carne bovina do mundo, tendo abatido mais de 39 milhões de cabeças e contando com o maior rebanho mundial (209 milhões de cabeças). É importante dizer que $80 \%$ da carne bovina consumida pelos brasileiros é produzida no próprio país (Embrapa, 2020).

No ano de 2018 ocorreu o aumento da produção de carne bovina no Brasil, alcançando um resultado de 10,96 milhões de toneladas, desse montante, $20,1 \%$ foi destinado para a exportação e o fruto desta saída intensa de carne brasileira foi uma receita de US\$ 6,57 bilhões, um crescimento de 7,9\%, comparado ao ano de 2017. Isto possibilitou a Associação Brasileira das Indústrias Exportadoras de Carne (ABIEC) a afirmar que se trata do maior volume já alcançado entre todos os países exportadores, o que consolida ainda mais a liderança do país nesse segmento (ABIEC,2019). 
É válido dizer que o Brasil possui o maior rebanho comercial mundial, nesse ponto perde somente para a Índia, que, no entanto, possui apenas $4,1 \%$ de seu rebanho total voltado para consumo. No que se refere a variação de produção de 2008 a 2018, o Brasil foi o país que mais teve crescimento de produção de carne, seguido da China e Turquia (ABIEC, 2019).

De acordo com a Food and Agriculture Organization (FAO), entre as unidades da federação, o Rio Grande do Sul é atualmente o $7^{\circ}$ maior produtor do Brasil e registrou uma produção de 13.164.945 cabeças em média no triênio 2016-2018. Considerando a última década, pode-se afirmar que o Estado manteve estável o seu rebanho, no entanto, em período mais longo a produção gaúcha apresentou uma queda em sua participação, passando de 8\% em 2000 para 6\% em 2018. De outro lado, a cadeia produtiva, uma das mais tradicionais do Estado, possui grande importância econômica social e poder de integração regional, possibilidade de aumento de valor agregado de seus produtos finais e de melhoria da pauta de exportações (Atlas, 2019).

\subsection{As cinco forças competitivas de Porter}

Recomendado para estudos da competitividade empresarial, as cinco forças de Porter (figura 3) englobam as regras da concorrência que determinam a habilidade de empresas para que obtenham taxas de retorno sobre investimentos superiores ao custo de capital. Influenciam os preços, os custos e o investimento necessário da empresa em uma indústria, determinando assim sua rentabilidade (Porter, 1990).

Figura 3: Cinco Forças Competitivas.

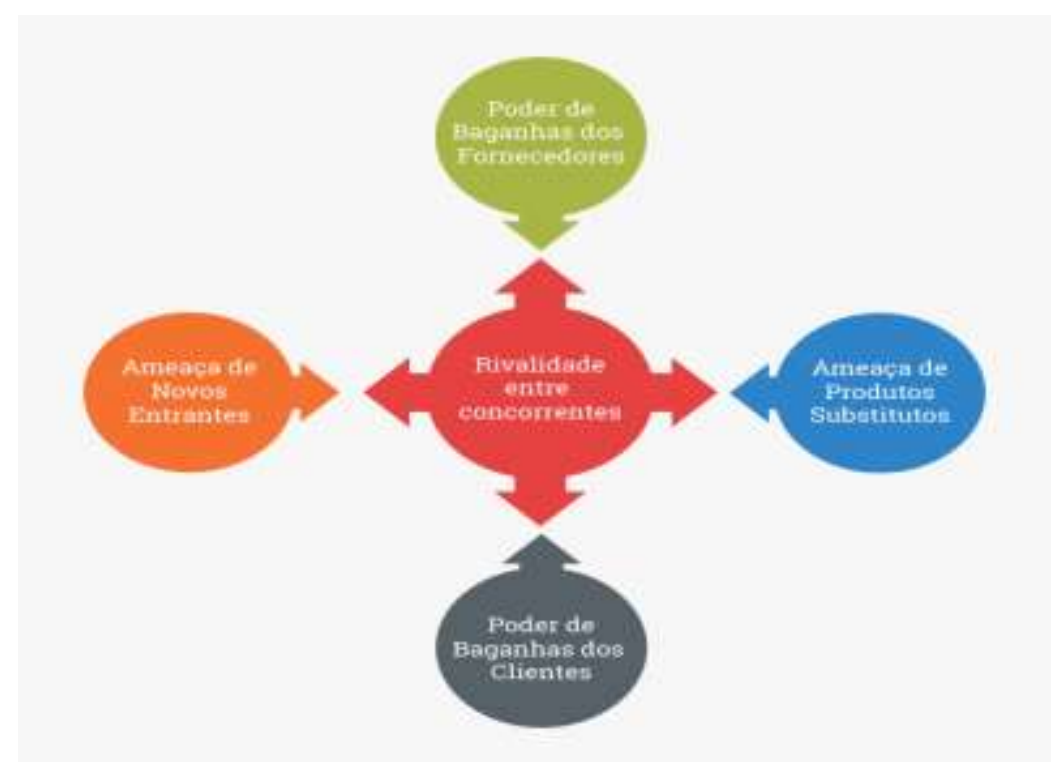

Fonte: Porter (1992, p. 4).

As cinco forças competitivas apresentam-se de maneira específica, em contextos de cada organização. Para Porter (1990) cada indústria expressa com mais ou menos vigor cada uma dessas forças, sendo que elas podem modificar-se à medida que a indústria evolui. Esse vigor é uma função da estrutura industrial ou das características técnicas e econômicas subjacentes de uma indústria.

Portanto, entre as cinco forças competitivas, o poder de barganha dos clientes é essencial para a análise da competitividade e estratégia organizacional. De acordo com Porter (2004) os clientes competem com a indústria, forçando os preços para baixo, barganhando por melhor qualidade ou mais serviços e jogando os concorrentes uns contra os outros, diminuindo a rentabilidade da indústria. 
Assim, a outra força competitiva diz respeito aos produtos substitutos. No entender de Porter (2004), todas as empresas no conjunto das indústrias, estão competindo, em termos amplos, com indústrias que fabricam produtos substitutos. Os substitutos reduzem os retornos potenciais de uma indústria, colocando um teto nos preços que as empresas podem fixar lucro. Quanto mais atrativa a alternativa de preço-desempenho oferecida pelos produtos substitutos, mais firme será a pressão sobre os lucros da indústria.

Entende-se que entre as cinco forças competitivas, a entrada de novos concorrentes representa a disputa pelo mercado entre as empresas do mesmo setor. Para Porter $(2004$, p.7) "as novas empresas entram para uma indústria trazendo nova capacidade, aliada ao desejo de ganhar uma parcela do mercado e frequentemente recursos substanciais". Ainda conforme Porter (2004, p.7): "A ameaça de entrada em uma indústria depende das barreiras de entrada existentes, em conjunto com a reação que o novo concorrente pode esperar da parte dos concorrentes já existentes".

O poder de barganha dos fornecedores também representa uma força competitiva. Segundo Porter (2004, p.29) "Quando os fornecedores vendem para várias indústrias e uma determinada indústria não representa uma fração significativa das vendas, os fornecedores estão muito propensos a exercer seu poder".

A rivalidade entre os concorrentes também representa uma força competitiva importante, no entender de Porter (2004, p.10) "Algumas formas de concorrência, notadamente a concorrência de preços, são altamente instáveis, sendo bastante provável que deixem toda a indústria em pior situação do ponto de vista da rentabilidade".

Deste modo, percebe-se que as cinco forças competitivas de Porter afetam a competitividade organizacional, tanto no ambiente interno quanto no externo. A relação da empresa, com o contexto do ambiente, em que está inserida, que é de suma importância, quando da formulação de estratégias e da implementação de um planejamento, já que esta norteia as ações para o suprimento das necessidades e fomentação das potencialidades da mesma (Vargas et. al., 2013).

Uma das ferramentas utilizadas para criar estratégias, tanto no ambiente interno, quanto no externo, é a análise SWOT. Segundo Kotler e Keller (2006, p. 50) "A avaliação global das forças, fraquezas, oportunidades e ameaças é denominada análise SWOT (dos termos em inglês strengths, weaknesses, opportunities, threats). Ela envolve o monitoramento dos ambientes externo e interno".

Os pontos fortes e fracos fazem referência ao ambiente interno da organização. Conforme Oliveira (2014, p. 37) "Ponto forte é a diferenciação conseguida pela empresa - variável controlável - que lhe proporciona uma vantagem operacional no ambiente empresarial (onde estão os assuntos não controláveis pela empresa)". Já o ponto fraco, segundo Oliveira (2014, p. 37) "é uma situação inadequada na empresa - variável controlável - que lhe proporciona uma desvantagem operacional no ambiente empresarial".

As oportunidades e ameaças fazem referência ao macroambiente ou ambiente externo. Para Oliveira (2014, p. 37) "Oportunidade é a força ambiental incontrolável pela empresa, que pode favorecer sua ação estratégica, desde que conhecida e aproveitada, satisfatoriamente, enquanto perdura”. Já ameaça, de acordo com Oliveira (2014, p37) "[...] é a força ambiental incontrolável pela empresa, que cria obstáculos à sua ação estratégica, mas que poderá ou não ser evitada, desde que conhecida em tempo hábil”.

\section{Metodologia}

Esta pesquisa possuí abordagem qualitativa (Vergara, 2008). Classifica-se, quanto aos objetivos, como exploratória e descritiva. No entendimento de Gil (2014), a principal finalidade da pesquisa exploratória é desenvolver, esclarecer e modificar conceitos e ideias, tendo em vista a formulação de problemas mais precisos, ou hipóteses para estudos posteriores. Assim, a pesquisa exploratória visou a aproximação do modelo das cinco forças de Portes à realidade da indústria frigorífica brasileira.

A pesquisa descritiva caracterizou-se pelo estudo das características do mercado da carne bovina brasileira, pela 
experiência da indústria frigorífica do Noroeste do Rio Grande do Sul. As pesquisas descritivas têm como objetivo principal a descrição das características de determinada população ou fenômeno, ou o estabelecimento de relação entre variáveis. Podem ser consideradas como pesquisas descritivas as que possuem por objetivo estudar as características de um grupo, como idade, sexo, nível de renda e outros. Também são incluídas neste grupo as pesquisas que têm por objetivo levantar as opiniões, atitudes e crenças de uma população (Gil, 2014).

Como procedimentos técnicos da pesquisa é destacado o estudo de caso em uma indústria frigorífica do Noroeste do Estado do Rio Grande do Sul. Um estudo de caso "é uma investigação empírica que investiga um fenômeno contemporâneo dentro de seu contexto da vida real, especialmente quando os limites entre o fenômeno e o contexto não estão claramente definidos" (Yin, 2001, p. 32).

Foi realizada entrevista semiestruturada com um dos gestores do frigorífico, objeto deste estudo, a fim de verificar o contexto da empresa em relação às cinco forças competitivas de Porter. A análise dos resultados, contou com a Análise de Conteúdo, de Bardin (2010, p. 44), que a define como:

Um conjunto de técnicas de análise das comunicações visando obter procedimentos sistemáticas e objetivos de descrição do conteúdo das mensagens indicadores (quantitativos ou não) que permitam a inferência de conhecimentos relativos às condições de produção; recepção (variáveis inferidas) destas mensagens.

\section{Resultados e Discussão}

O frigorífico, objeto deste estudo, localiza-se na Região Noroeste do estado do Rio Grande do Sul. Com mais de duas décadas de atuação no mercado da carne bovina, a empresa trabalha com abate e distribuição de variados tipos de cortes bovinos, incluindo a linha de novilho precoce, miúdos e embalagem à vácuo.

Segundo a empresa os produtos podem ser comercializados em todo o Brasil. Isso é possível graças a certificação do Sistema Brasileiro de Inspeção de Produtos de Origem Animal (SISBI-POA), que faz parte do Sistema Unificado de Atenção a Sanidade Agropecuária (SUASA), padroniza e harmoniza os procedimentos de inspeção de produtos de origem animal para garantir a inocuidade e segurança alimentar.

\subsection{Análise das cinco forças de Porter}

A seguir tem-se a descrição e análise dos resultados da pesquisa, contemplando a análise das cinco forças de Porter e, por fim, a apresentação da matriz SWOT da organização objeto de estudo.

\subsubsection{Poder de Barganha dos Clientes}

Quando o gestor foi questionado se o volume da compra interfere no preço de venda, o mesmo relatou que existe essa interferência, pois o preço varia de acordo com o volume de compras. Desta forma, percebe-se que o frigorífico objeto deste estudo, oferece vantagens para os clientes que adquirem maior quantidade de produtos. Os principais clientes da empresa são os supermercados em sua região de atuação.

O gestor do frigorífico também foi questionado se, nos últimos anos, a demanda permaneceu constante ou têm oscilado positiva ou negativamente. De acordo com o gestor, a demanda tem oscilado positivamente, o que indica a manutenção dos negócios da empresa e a possibilidade de novos negócios no setor da carne bovina. Considerando que os frigoríficos aumentaram seu faturamento em cerca de 16\% do ano de 2017 para o ano de 2018 (ABIEC, 2019), a demanda crescente pela carne bovina é um fenômeno constatado não apenas localmente, mas sim em nível nacional e internacional. 


\subsubsection{Ameaça de Produtos Substitutos}

Os cortes de carne bovina disputam a preferência dos consumidores com outros tipos de carne, além de produtos com potencial de substituição. Por isso, o gestor da indústria frigorífica foi questionado sobre a probabilidade da substituição da carne bovina pela de frango. Em resposta, o mesmo afirmou que em alguns períodos pode haver essa substituição, entretanto, a carne bovina continua no topo da preferência dos consumidores. Ainda, questionado sobre a possibilidade de substituição da carne bovina pela suína, o gestor afirmou que dificilmente os consumidores farão essa troca, pois o churrasco de carne bovina faz parte da cultura das pessoas, especialmente do povo gaúcho, o qual tem por tradição preparar o churrasco nos finais de semana ou em eventos comemorativos.

Dentre os diversos fatores que afetam a demanda pela carne bovina, os mais importantes são os de ordem econômica, como a renda da população, o preço da carne e o preço de proteínas concorrentes (Embrapa, 2020). Considerando a ameaça de substituição da carne bovina nos próximos anos, o gestor da indústria frigorífica salientou que não vê ameaças com forte potencial. No entanto, também afirmou que a carne de frango pode substituir a carne bovina em alguns períodos específicos. Há de se considerar também, como ameaça ao consumo de carne bovina, o aumento da conscientização dos consumidores frente aos impactos ambientais causados pela pecuária, pois é sabido que a criação de gado de corte é altamente poluidora. A conscientização parte também de órgãos internacionais, como a Organização das Nações Unidas (ONU).

De acordo com os 17 objetivos para o desenvolvimento sustentável incluídos na Agenda 2030 pela Organização das Nações Unidas, a pecuária de corte pode ser relacionada ao objetivo de número dois, o qual possuí como tema "fome zero e agricultura sustentável”. Na descrição deste objetivo, a ONU afirma que é necessário:

Até 2030, garantir sistemas sustentáveis de produção de alimentos e implementar práticas agrícolas resilientes, que aumentem a produtividade e a produção, que ajudem a manter os ecossistemas, que fortaleçam a capacidade de adaptação às mudanças climáticas, às condições meteorológicas extremas, secas, inundações e outros desastres, e que melhorem progressivamente a qualidade da terra e do solo.

Mesmo havendo um consenso internacional frente ao consumo sustentável da carne bovina, o que implicaria na redução de seu consumo, o cenário vivenciado pela indústria frigorífica e demais elos da cadeia produtiva não é desanimador. Pelo contrário, a produção e o consumo brasileiro vêm crescendo nos últimos anos, influenciado pela forte demanda de países do continente asiático.

Conforme registro do Movimento Nacional de Produtores (2020) o Brasil deve produzir 10,5 milhões de toneladas de carne bovina em 2020, segundo estimativa do Departamento de Agricultura dos Estados Unidos (USDA). Se confirmados, estes volumes representam, respectivamente alta de 3,4\% comparado ao ano passado. O USDA atribui o aumento da produção de proteína bovina à maior produtividade, exportações recordes e ao fortalecimento do mercado doméstico. O órgão prevê também que o país exporte 2,53 milhões de toneladas de carne bovina em 2020, $10 \%$ a mais que o comercializado para o exterior em 2019, impulsionado principalmente pela firme demanda de China e Hong Kong.

\subsubsection{Ameaça de novos Entrantes}

O gestor da indústria frigorífica foi interrogado se percebe como alta, média ou baixa a probabilidade da entrada de novas indústrias frigoríficas em sua região de atuação. O mesmo declarou que a probabilidade é baixa, haja vista que são muitas as exigências fiscais e ambientais, e a localização geográfica do noroeste gaúcho é insatisfatória para novas instalações.

Assim, a pesquisa permite afirmar que a probabilidade de novos entrantes no setor frigorífico é baixa no Noroeste do Rio Grande do Sul. Entretanto, essa situação pode ser invertida em outras localidades brasileiras, onde a localização geográfica seja favorável ao abate de bovinos. De todo modo, as exigências sanitárias e ambientais são estabelecidas em todo o território 
nacional, o que impõem as mesmas dificuldades para a instalação da indústria frigorífica, seja no Rio Grande do Sul ou nos demais estados brasileiros.

Ainda, questionado o gestor, se a empresa está preparada para a entrada de novos concorrentes, o mesmo afirmou que a indústria frigorífica realiza planejamentos e análises acerca da situação econômica e possíveis concorrentes, sem especificar nenhum aspecto levado em conta nesta análise.

\subsubsection{Poder de Barganha dos Fornecedores}

Na pesquisa realizada com o gestor do frigorífico, o mesmo apontou que os principais fornecedores da empresa são os produtores de gado de corte do estado do Rio Grande do Sul, além de uma empresa que fornece embalagens plásticas e outra que fornece produtos para higienização. Como a indústria objeto de estudo não detém parcela significativa do mercado, os apontamentos de Porter (1992) indicam que seus fornecedores detêm forte poder de barganha.

Ainda, o estudo identificou que nenhum dos produtos que os fornecedores entregam para a indústria frigorífica, possuem características únicas ou diferenciação, que os impeça de serem substituídos, porém, o gestor da empresa ressaltou que a qualidade e o preço são levados em conta nas negociações que envolvem fornecedores.

\subsubsection{Rivalidade entre Concorrentes}

$\mathrm{Na}$ entrevista com gestor, ao falar sobre os maiores concorrentes, no setor da indústria frigorífica, o mesmo relatou que existem duas empresas que se destacam em sua região de atuação. O gestor ainda destacou que os diferenciais da indústria frigorífica para destacar-se em relação aos concorrentes são os produtos de alta qualidade oferecidos à preços atrativos, sempre com ótimo relacionamento com clientes.

Entende-se que a qualidade do produto, aliado ao relacionamento adequado com o cliente, são instrumentos que criam vantagem competitiva para a empresa. De acordo com Porter (1992) a vantagem competitiva origina-se essencialmente no valor que uma empresa consegue criar para seus clientes e que supera o custo de produção.

Embora o frigorífico tenha pontos fortes em relação aos concorrentes, seu gestor apontou que existe uma fraqueza relacionada ao volume de produção, o qual é significativamente inferior ao seu principal concorrente. Enquanto a indústria frigorífica possui capacidade de abate diária de 72 bovinos, o principal concorrente consegue abater 250 bovinos por dia, e esse maior volume de abate acaba gerando vantagem no momento de estabelecer o preço de venda.

\subsection{Análise SWOT da indústria frigorífica}

Considerando os dados obtidos na pesquisa empírica, foi elaborada a matriz SWOT do frigorífico estudado, demonstrada pelo Quadro 1. Segundo Kotler e Keller (2006, p. 50) “A avaliação global das forças, fraquezas, oportunidades e ameaças é denominada análise SWOT (dos termos em inglês strengths, weaknesses, opportunities, threats). Ela envolve o monitoramento dos ambientes externo e interno". 
Quadro 1: Matriz SWOT da indústria frigorífica objeto de estudo.

\begin{tabular}{|l|ll|}
\hline $\begin{array}{l}\text { FORÇAS } \\
\text { Qualidade e diferenciação do produto; } \\
\text { Certificação SISBI-POA. }\end{array}$ & $\begin{array}{l}\text { FRAQUEZAS } \\
\text { Capacidade de abate inferior ao principal } \\
\text { concorrente; } \\
\text { Barganha dos clientes pela redução dos } \\
\text { preços. }\end{array}$ \\
\hline $\begin{array}{l}\text { OPORTUNIDADES } \\
\text { Aumento na demanda pela carne bovina; } \\
\text { Distribuição para outras localidades além do } \\
\text { Noroeste do RS. }\end{array}$ & $\begin{array}{l}\text { AMEAÇAS } \\
\text { Crescimento da cultura vegana e e } \\
\text { vegetariana; } \\
\text { Substituição da carne bovina pela de frango. }\end{array}$ \\
\hline
\end{tabular}

Fonte: Autores (2020).

No ambiente interno da empresa investigada, seus pontos fortes são relacionados aos produtos comercializados, pois estes possuem características que agregam valor aos cortes de carne bovina, além de sua comercialização ser permitida em todo o território nacional. Já em relação às principais fraquezas, são destacadas a menor capacidade de abate em relação ao principal concorrente, além da barganha dos clientes por descontos, o que acaba limitando a margem de lucro da empresa.

As principais oportunidades para a empresa são o aumento na demanda pela carne bovina, uma vez que seu gestor apontou que a demanda tem oscilado positivamente, além da expansão da distribuição dos produtos para outras localidades brasileiras. As principais ameaças dizem respeito crescimento da cultura vegana e vegetariana, reduzindo assim o consumo da carne, e também a substituição da carne bovina pela de frango, já que esta possui menor valor e, principalmente em períodos de crise econômica, acaba sendo a melhor opção de compra pelos consumidores.

\section{Considerações Finais}

O objetivo do presente estudo foi investigar a competitividade da carne bovina brasileira à luz do modelo das cinco forças de Porter. Para responder a esse desafio, além dos estudos nas referências bibliográfica, foi realizada uma pesquisa em uma indústria frigorífica na Região Noroeste do estado do Rio Grande do Sul, que possui certificação para comercializar os cortes de carne bovina em todo o território brasileiro.

A análise das cinco forças de Porter foi fundamental para entender as forças, fraquezas, oportunidades e ameaças do frigorifico. O principal ponto forte do empreendimento é a qualidade dos produtos, os quais apresentam características que agregam valor e os diferenciam em relação aos concorrentes. A principal fraqueza é relacionada à capacidade de abate, a qual é significativamente inferior ao maior concorrente.

Com relação ao ambiente externo, a principal oportunidade é relacionada ao aumento na demanda pela carne bovina, propiciando assim a chance de novos negócios. A principal ameaça diz respeito à redução no consumo da carne bovina, com o crescimento da cultura vegana ou vegetariana, ou pela crise econômica, a qual revela o consumo de produtos substitutos, como a carne de frango.

A competitividade da carne bovina, especialmente no Noroeste do Rio Grande do Sul, é constatada pela manutenção da demanda, mesmo com o país enfrentando um cenário de grave crise econômica. Assim, considerando a importância da cadeia produtiva da carne bovina no Brasil, sugere-se que pesquisas futuras busquem ampliar as pesquisas, analisando a competitividade da carne bovina, em outras regiões brasileiras, bem como possíveis caminhos para a exportação. Novas pesquisas também podem analisar outros elos da cadeia produtiva da carne bovina, além da indústria frigorífica. 


\section{Referências}

ABIEC. (2019). Beef REPORT: perfil da pecuária no Brasil. Associação Brasileira Das Industrias Exportadora de Carne (ABIEC). http://abiec.com.br/publicacoes/beef-report-2019/.

Atlas. (2019). Bovinos: o RS possui 6,5\% do rebanho bovino do Brasil. (4a ed.), Atlas. https://atlassocioeconomico.rs.gov.br/bovinos.

Bardin, L. (2010). Análise de conteúdo. Edições 70, Ltda.

Batalha, M. (1997). Gestão agroindustrial. Atlas.

Braga, M. J. (2010). Redes, alianças estratégicas e intercooperação: o caso da cadeia produtiva de carne bovina. Revista Brasileira de Zootecnia, 39 (supl especial), 11-16.

Buainain, A. M. \& Batalha, M. O. (2007). Série agronegócios: cadeia produtiva da carne bovina. 8, 1-88. http://repiica.iica.int/docs/B0585p/B0585p.pdf.

Embrapa. (2020). Abate da carne bovina. Empresa de Pesquisa Agropecuária (Embrapa). https://www.embrapa.br/qualidade-da-carne/carne-bovina/abate.

Embrapa. (2020). Processamento e distribuição da carne bovina. Empresa de Pesquisa Agropecuária (Embrapa). https://www.embrapa.br/qualidade-dacarne/carne-bovina/processamento-e-distribuicao.

Ferreira, G. C., \& de Barcellos, M. D. (2011). Vantagens e desvantagens das alianças estratégicas: uma análise sob a ótica dos agentes da cadeia produtiva da carne bovina. Organizações Rurais \& Agroindustriais, 8(1).

Ferreira, G. C., \& Padula A. D. (2002). Gerenciamento de cadeias de suprimento: novas formas de organização na cadeia da carne bovina do Rio Grande do Sul. Revista de Administração Contemporânea, 6(2), 167-184.

Gil, A. C. (2014). Métodos e técnicas de pesquisa social. Atlas. (6a ed.),

Instituto Euvaldo Lodi-IEL; Confederação Nacional da Agricultura-CNA; Serviço Brasileiro de Apoio às Micro e Pequenas Empresas-SEBRAE. (2020). Estudo sobre a eficiência econômica e competitividade da cadeia agroindustrial da pecuária de corte no Brasil. http://www.dep.ufscar.br/docentes/hildo/Cadeias/Carne\%20bovina\%20BR.pdf.

Kotler, P.; \& Keller, L. K. (2006). Administração de Marketing. Traduzindo por Mônica Rosenberg, Cláudia Freire, Brasil Ramos Fernandes. 12º ed. São Paulo: Prentice Hall.

Ludtke, C. B., et al. (2020). Abate humanitário de bovinos: Steps- Melhorando o bem-estar animal no abate. https://www.gov.br/agricultura/ptbr/assuntos/producao-animal/arquivos-publicacoes-bem-estar-animal/programa-steps-2013-abate-humanitario-de-bovinos.pdf.

ONU. (2020). Objetivos de Desenvolvimento Sustentável. Organização das Nações Unidas (ONU). https://nacoesunidas.org/pos2015/ods2/.

Porter, M. E. (2004). Estratégia competitiva: Técnicas para a Análise da Indústria e da Concorrência. Elsevier.

Porter, M. E. (1990). Vantagem competitiva: criando e sustentando um desempenho superior. Campus.

Porter, M. E. (1992). Vantagem competitiva: criando e sustentando um desempenho superior. (7a ed.), Ed Campus:

Reis, F. (2020). A pecuária brasileira e o mercado das carnes especiais. https://www.scotconsultoria.com.br/noticias/artigos/48906/a-pecuaria-brasileira-e-omercado-de-carnes-especiais.htm.

Vargas, K. S., Moura, G., Bueno, D., \& Paim, E. (2013). A cadeia de valores e as cinco forças competitivas como Metodologia de planejamento estratégico. Revista Brasileira de Estratégia, 6(1), 11-22.

Vergara, S. C. (2008). Métodos de pesquisa em administração. (3a ed.), Atlas.

Vieira, A. N. de C., Sartori, A., Moraes, F. C. de, \& Siqueira, R. N. de. (2020). A Elasticidade De Transmissão De Preços Entre Os Elos De Mercado: Produtor, atacado e varejo na comercialização da carne bovina no período de 1997 a 2013. Revista Estudos E Pesquisas Em Administração, 4(2), 65-80.

Yin, R. K. (2001). Estudo de caso: planejamentos e métodos. (2a ed.), Bookman.

Zucchi, J. D.; \& Caixeta Filho, J. V. (2010). Panorama dos Principais Elos da Cadeia Agroindustrial da Carne Bovina Brasileira. Informações Econômicas (Impresso), 40: 18-33. 